\title{
NOTAS SOBRE A MEDIDA PROVISÓRIA 871/2019
}

\author{
Julio Pinheiro Faro Homem de Siqueira \\ Mestre em Direitos e Garantias Fundamentais pela FDV; \\ Pesquisador Mestre nos PPGD da FDV, UFRN e URI/SAN; \\ Professor de Direito Constitucional, Tributário e Previdenciário; \\ Servidor Público Federal no $1^{\circ}$ Juizado Especial Federal de \\ Volta Redonda/RJ. \\ julio.pfhs@gmail.com
}

Resumo: As presentes notas fornecem um panorama geral sobre as alterações feitas pela Medida Provisória 871, de 18/01/2019, na legislação previdenciária e assistencial, com foco específico sobre as inovações que impactem no processamento das varas federais previdenciárias.

Palavras-chave: Direito previdenciário. Medida Provisória 871/2019.

\section{Introdução}

A Medida Provisória - MPv 871, de 18/01/2019, apelidada de MP do Pente Fino, institui dois programas, um para a análise de benefícios com indícios de irregularidade e outro para a revisão de benefícios por incapacidade, bem como dois bônus de desempenho institucional, um para o monitoramento e análise de benefícios e outro para perícias médicas em benefícios por incapacidade. Além disso, a medida provisória traz algumas alterações importantes na legislação previdenciária e assistencial.

A justificativa para a edição da medida provisória e a fiscalização de todos os benefícios deferidos pelo Instituto Nacional do Seguro Social - INSS. Em que pesem as dúvidas sobre a constitucionalidade da espécie normativa, mormente no que pertine à sua urgência, ao princípio da proibição do retrocesso social e às premissas que a informam, o objetivo da presente nota não é o de apontar as suas possíveis inconstitucionalidades.

A proposta desta nota é mais simples e consiste em destacar quais as alterações na legislação previdenciária e assistencial, a fim de que se possa vislumbrar a influência da MPv 871/2019 sobre os processos judiciais nas varas federais previdenciárias. Portanto, algumas novidades trazidas pela medida provisória sequer são tratadas, dando-se atenção apenas às inovações que promovam alterações no processamento judicial. É importante 
sublinhar, nesse passo, que, sempre em sequência aos comentários é apresentado quadro comparativo entre o texto legal anterior e o novo.

\section{Direito intertemporal}

Antes, porém, de analisar as alterações promovidas, é importante estabelecer o critério temporal de aplicação dessas mudanças. Isso significa falar a respeito do direito intertemporal. Nesse sentido, convém registrar que os benefícios previdenciários, mais que os assistenciais, observam a regra do tempus regit actum, o que significa que eles são regulados pela lei vigente ao tempo em que ocorrido o respectivo fato gerador, com todos os seus complementos, ou, em outros termos, assim que preenchidos todos os requisitos necessários à sua concessão. Portanto, a nova regulamentação, provisoriamente firmada pela MPv 871, será aplicável apenas àqueles benefícios cujos fatos geradores ocorram durante a sua vigência.

Convém recordar que, pelo artigo 62 da Constituição da República Federativa do Brasil de 1988 (CRFB/1988), as medidas provisórias são espécies legislativas com prazo de duração previamente definido. Assim, salvo disposição em contrário em seu próprio corpo, elas produzem efeitos imediatos, mas vigem por 60 dias, prorrogáveis uma única vez por igual período, ou seja, a vigência máxima é de 120 dias, durante os quais deve o Congresso Nacional analisá-la com o propósito de transformá-la, ou não, em lei. Se, no prazo de 45 dias, contados de sua publicação, a MPv não for convertida em lei, ela tranca a pauta do Parlamento. Se ela for rejeitada ou perder a eficácia, em alguma das Casas do Congresso, é necessário editar um decreto legislativo para disciplinar os efeitos jurídicos gerados durante sua vigência. Caso o seu conteúdo for alterado, o texto passa a tramitar como projeto de lei. E, por fim, na hipótese de ser aprovada nas duas Casas, será enviada à Presidência da República, para sanção ou veto. Portanto, o primeiro dia de vigência da MPv 871/2019 é 18/01/2019 e o último, 17/05/2019.

No caso da MPv 871/2019, há três prazos distintos de vigência em seu corpo normativo:

(1) a alteração do $\S 3^{\circ}$ do artigo 74 da Lei de Benefícios da Previdência Social 8.213/1991 (LBPS) entra em vigor 120 dias após a publicação. Trata-se de vacância máxima, já que a alteração somente entrará em vigor com a conversão da MPv em Lei.

Redação anterior à MPv 871 Sem correspondência.
Redação dada pela MPv 871

Art. 74. (...) 


\begin{tabular}{|l|l|}
\hline & $3^{\circ}$. Ajuizada a ação judicial para \\
reconhecimento da condição de \\
dependente, este poderá requerer a sua \\
habilitação provisória ao benefício de \\
pensão por morte, exclusivamente para \\
fins de rateio dos valores com outros \\
dependentes, vedado o pagamento da \\
respectiva cota até o trânsito em julgado \\
da decisão judicial que reconhecer a \\
qualidade de dependente do autor da \\
ação.
\end{tabular}

(2) a alteração do § 13 do art. 20 da Lei Orgânica da Assistência Social 8.742/1993 (LOAS) entra em vigor 90 dias após a publicação.

\begin{tabular}{|l|l|}
\hline \multicolumn{1}{|c|}{ Redação anterior à MPv 871 } & \multicolumn{1}{|c|}{ Redação dada pela MPv 871 } \\
\hline Sem correspondência. & Art. 20. (...) \\
§ 13. O requerimento, a concessão e a \\
revisão do benefício ficam condicionados \\
à autorização do requerente para acesso \\
aos seus dados bancários, nos termos do \\
disposto no inciso V do $\S 3^{\circ}$ do art. $1^{\circ}$ da \\
Lei Complementar $\mathrm{n}^{\mathbf{0}} 105$, de 10 de \\
janeiro de 2001.
\end{tabular}

(3) todas as demais alterações entram em vigor na data da publicação.

As notas a seguir são feitas com base nas alterações que já estão em vigor. É conveniente sublinhar que todos os dispositivos legais se referem, prioritariamente, ao texto da MPv 871, e quando a ela não se referirem, será indicado o respectivo diploma legal.

\section{Programa de Revisão da concessão e manutenção de benefícios}

O artigo $1^{\circ}, \S 4^{\circ}$, estabelece que os processos judiciais de benefícios por incapacidade integrarão o Programa de Revisão e serão acompanhados por médicos peritos, o que abrange, conforme o artigo 10, caput, os peritos médicos federais, os peritos médicos da Previdência Social e os supervisores médico-periciais. Todos eles poderão receber, na forma do artigo $2^{\circ}$, II, um Bônus de Desempenho Institucional por Perícia Médica em Benefícios por Incapacidade (BPMBI), pago para cada perícia médica extraordinária no âmbito do Programa de Revisão, na forma que estabelecer ato do Secretário Especial de Previdência e Trabalho do Ministério da Economia. 
Na forma do artigo $10, \S 1^{\circ}$, esse ato "disporá sobre os critérios para seleção dos benefícios objeto das perícias extraordinárias", abrangendo: I - os "benefícios por incapacidade mantidos sem perícia pelo INSS por período superior a seis meses e que não possuam data de cessação estipulada ou indicação de reabilitação profissional"; II - os “benefícios de prestação continuada sem revisão por período superior a dois anos"; e III - os "outros benefícios de natureza previdenciária, assistencial, trabalhista ou tributária concedidos até a data de publicação desta Medida Provisória”. É importante notar que nem todos os processos judiciais de benefícios por incapacidade serão acompanhados, mas tão somente aqueles elencados no artigo $10, \S 1^{\circ}$, na forma dos artigos 15 e 16 :

Art. 15. Ato do Secretário Especial de Previdência e Trabalho do Ministério da Economia disporá sobre:

I - os critérios gerais a serem observados para a aferição, o monitoramento e o controle da realização das perícias médicas de que trata o art. 10, para fins de concessão do BPMBI;

II - o quantitativo diário máximo de perícias médicas, nos termos do disposto no art. 10, por perito médico, e a capacidade operacional ordinária de realização de perícias médicas pelo perito médico e pela Agência da Previdência Social do INSS;

III - a forma de realização de mutirão das perícias médicas; e

IV - os critérios de ordem de prioridade para o agendamento dos benefícios a serem revistos, tais como a data de concessão do benefício e a idade do beneficiário.

Art. 16. Ato do Ministro de Estado da Economia estabelecerá os procedimentos necessários para a realização das perícias de que trata o art. 10.

Seguindo esse propósito de fiscalização dos benefícios concedidos, para apurar eventuais irregularidades e corrigi-las, o artigo 24 trouxe alterações importantes ao capítulo sobre a modernização da Previdência Social da Lei Orgânica da Seguridade Social 8.212/1991 (LOSS). Como se pode notar da leitura da nova redação dada ao artigo 69 da LOSS, o propósito de apurar as irregularidades ou erro materiais nas concessões foi mantido, com o propósito de economizar recursos. Todavia, ao contrário da redação anterior, a nova destrincha melhor o procedimento administrativo a ser adotado.

A notificação do beneficiário, no Programa de Revisão Permanente, instituído pelo artigo 69 da LOSS, determina o início da contagem do prazo de 10 dias para que defenda a regularidade ou a ausência de erros materiais na concessão de seu benefício. O 
dispositivo prevê três formas para a notificação: pela rede bancária, por meio eletrônico ou por via postal com aviso de recebimento, que pode ser assinado por qualquer pessoa. Caso não seja apresentada a defesa ou esta seja insuficiente, o benefício será suspenso. Com a suspensão, começa a correr o prazo de 30 dias para recurso administrativo. O início do prazo é a data em que foi suspenso o benefício, no caso de revelia, ou a data da notificação sobre a suspensão, no caso de defesa insuficiente. Decorrido o prazo ou julgado ou não acolhido o recurso, o benefício será cessado.

Além disso, a MPv estabelece, também, a necessidade de recenseamento anual dos beneficiários, o que ocorrerá mediante o comparecimento antecedido de agendamento prévio ou perante a instituição financeira pagadora, conforme ato do Presidente do INSS, a fim de que o beneficiário faça prova de vida. No caso de suspeita de fraude, a autarquia poderá fazer uso de pesquisa externa e de cruzamento de danos com outros órgãos que mantenham cadastros, inclusive biométricos.

As novidades estão na tabela abaixo:

\begin{tabular}{|c|c|}
\hline Redação anterior à MPv 871 & Redação dada pela MPv 871 \\
\hline $\begin{array}{l}\text { Art. 69. O Ministério da Previdência e } \\
\text { Assistência Social e o Instituto Nacional } \\
\text { do Seguro Social - INSS manterão } \\
\text { programa permanente de revisão da } \\
\text { concessão e da manutenção dos benefícios } \\
\text { da Previdência Social, a fim de apurar } \\
\text { irregularidades e falhas existentes. }\end{array}$ & $\begin{array}{l}\text { Art. 69. O Instituto Nacional do Seguro } \\
\text { Social - INSS manterá programa } \\
\text { permanente de revisão da concessão e da } \\
\text { manutenção dos benefícios por ele } \\
\text { administrados, a fim de apurar } \\
\text { irregularidades ou erros materiais. }\end{array}$ \\
\hline $\begin{array}{l}\S 1^{\circ} \text { Havendo indício de irregularidade na } \\
\text { concessão ou na manutenção de benefício, } \\
\text { a Previdência Social notificará o } \\
\text { beneficiário para apresentar defesa, } \\
\text { provas ou documentos de que dispuser, no } \\
\text { prazo de trinta dias. }\end{array}$ & $\begin{array}{l}\S 1^{\circ} \text { Na hipótese de haver indícios de } \\
\text { irregularidade ou erros materiais na } \\
\text { concessão, na manutenção ou na revisão } \\
\text { do benefício, o INSS notificará o } \\
\text { beneficiário, o seu representante legal ou } \\
\text { o seu procurador para, no prazo de dez } \\
\text { dias, apresentar defesa, provas ou } \\
\text { documentos dos quais dispuser. }\end{array}$ \\
\hline $\begin{array}{l}\S 2^{\circ} \text { A notificação a que se refere o } \\
\text { parágrafo anterior far-se-á por via postal } \\
\text { com aviso de recebimento (...). }\end{array}$ & $\begin{array}{l}\S 2^{\circ} \text { A notificação a que se refere o } \S 1^{\circ} \\
\text { será feita: } \\
\text { I - preferencialmente por rede bancária ou } \\
\text { notificação por meio eletrônico, conforme } \\
\text { previsto em regulamento; ou } \\
\text { II - por via postal, por carta simples, } \\
\text { considerado o endereço constante do } \\
\text { cadastro do benefício, hipótese em que o } \\
\text { aviso de recebimento será considerado } \\
\text { prova suficiente da notificação. }\end{array}$ \\
\hline
\end{tabular}




\begin{tabular}{|c|c|}
\hline Sem correspondência. & $\begin{array}{l}\S 3^{\circ} \text { A defesa poderá ser apresentada por } \\
\text { canais de atendimento eletrônico } \\
\text { definidos pelo INSS. }\end{array}$ \\
\hline $\begin{array}{l}\S 2^{\circ} .(\ldots) \text { e, não comparecendo o } \\
\text { beneficiário nem apresentando defesa, } \\
\text { será suspenso o benefício, com notificação } \\
\text { ao beneficiário por edital resumido } \\
\text { publicado uma vez em jornal de circulação } \\
\text { na localidade. }\end{array}$ & $\begin{array}{l}\S 4^{\circ} \text { O benefício será suspenso na hipótese } \\
\text { de não apresentação da defesa no prazo } \\
\text { estabelecido no } \S 1^{\circ} \text {. }\end{array}$ \\
\hline $\begin{array}{l}\S 3^{\circ} \text { Decorrido o prazo concedido pela } \\
\text { notificação postal ou pelo edital, sem que } \\
\text { tenha havido resposta, ou caso seja } \\
\text { considerada pela Previdência Social como } \\
\text { insuficiente ou improcedente a defesa } \\
\text { apresentada, o benefício será cancelado, } \\
\text { dando-se conhecimento da decisão ao } \\
\text { beneficiário. }\end{array}$ & $\begin{array}{l}\S 5^{\circ} \text { O benefício será suspenso na hipótese } \\
\text { de a defesa a que se refere o } \S 1^{\circ} \text { ser } \\
\text { considerada insuficiente ou improcedente } \\
\text { pelo INSS, que deverá notificar o } \\
\text { beneficiário quanto à suspensão do } \\
\text { benefício e lhe conceder prazo de trinta } \\
\text { dias para interposição de recurso. }\end{array}$ \\
\hline Sem correspondência. & $\begin{array}{l}\S 6^{\circ} \text { Decorrido o prazo de trinta dias após } \\
\text { a suspensão a que se refere o } \S 5^{\circ} \text {, sem que } \\
\text { o beneficiário, o seu representante legal ou } \\
\text { o seu procurador apresente recurso } \\
\text { administrativo junto aos canais de } \\
\text { atendimento do INSS ou a outros canais } \\
\text { autorizados, o benefício será cessado. }\end{array}$ \\
\hline $\begin{array}{l}\S 4^{\circ} \text {. Para efeito do disposto no caput deste } \\
\text { artigo, o Ministério da Previdência Social } \\
\text { e o Instituto Nacional do Seguro Social - } \\
\text { INSS procederão, no mínimo a cada } 5 \\
\text { (cinco) anos, ao recenseamento } \\
\text { previdenciário, abrangendo todos os } \\
\text { aposentados e pensionistas do regime } \\
\text { geral de previdência social. }\end{array}$ & $\begin{array}{l}\S 7^{\circ} \text { Para fins do disposto no caput, o INSS } \\
\text { poderá realizar recenseamento para } \\
\text { atualização do cadastro dos beneficiários, } \\
\text { abrangidos os benefícios administrados } \\
\text { pelo INSS, observados o disposto no } \\
\text { inciso III ao inciso V do } \S 8^{\circ} \text {. }\end{array}$ \\
\hline Sem correspondência. & $\begin{array}{l}\S 8^{\circ} \text { Aqueles que receberem benefícios } \\
\text { realizarão anualmente a comprovação de } \\
\text { vida nas instituições financeiras, por meio } \\
\text { de atendimento eletrônico com uso de } \\
\text { biometria ou por qualquer meio definido } \\
\text { pelo INSS que assegure a identificação do } \\
\text { beneficiário, observadas as seguintes } \\
\text { disposições: } \\
\text { I - a prova de vida e a renovação de senha } \\
\text { serão efetuadas por aquele que receber o } \\
\text { benefício, mediante identificação por } \\
\text { funcionário da instituição, quando } \\
\text { realizada nas instituições financeiras; } \\
\text { II - a prova de vida poderá ser realizada } \\
\text { pelo representante legal ou pelo } \\
\text { procurador do beneficiário legalmente } \\
\text { cadastrado no INSS ou na instituição } \\
\text { financeira responsável pelo pagamento; }\end{array}$ \\
\hline
\end{tabular}




\begin{tabular}{|c|c|}
\hline & $\begin{array}{l}\text { III - a prova de vida de segurados com } \\
\text { idade igual ou superior a sessenta anos } \\
\text { será objeto de prévio agendamento, que } \\
\text { será disciplinado em ato do Presidente do } \\
\text { INSS; } \\
\text { IV - o INSS disporá de meios, incluída a } \\
\text { realização de pesquisa externa, que } \\
\text { garantam a identificação e o processo de } \\
\text { fé de vida para pessoas com dificuldades } \\
\text { de locomoção e idosos acima de oitenta } \\
\text { anos que recebam benefícios; e } \\
\text { V - o INSS poderá bloquear o pagamento } \\
\text { do benefício encaminhado às instituições } \\
\text { financeiras até que o beneficiário atenda à } \\
\text { convocação, permitida a liberação do } \\
\text { pagamento automaticamente } \\
\text { instituição financeira. }\end{array}$ \\
\hline Sem correspondência. & $\begin{array}{l}\S 9^{\circ} \text { Se não for possível realizar a } \\
\text { notificação de que trata o } \S 2^{\circ} \text {, o INSS } \\
\text { poderá suspender cautelarmente o } \\
\text { pagamento de benefícios nas hipóteses de } \\
\text { suspeita de fraude ou irregularidade } \\
\text { constatadas por meio de prova pré- } \\
\text { constituída. }\end{array}$ \\
\hline Sem correspondência. & $\begin{array}{l}\S 10 . \mathrm{Na} \text { hipótese prevista no } \S 9^{\circ} \text {, } \\
\text { apresentada a defesa a que se refere o } \S 1^{\circ} \text {, } \\
\text { o pagamento do benefício será reativado } \\
\text { até a conclusão da análise pelo INSS. }\end{array}$ \\
\hline Sem correspondência. & $\begin{array}{l}\S 11 \text {. Os recursos interpostos de decisão } \\
\text { que tenha suspendido o pagamento do } \\
\text { benefício, nos termos do disposto no } \S 9^{\circ} \text {, } \\
\text { terão prioridade de tramitação em todas as } \\
\text { instâncias administrativas. }\end{array}$ \\
\hline Sem correspondência. & $\begin{array}{l}\S 12 . \text { Os recursos de que tratam os } \S 5^{\circ} \text { e } \S \\
6^{\circ} \text { não terão efeito suspensivo. }\end{array}$ \\
\hline Sem correspondência. & $\begin{array}{l}\text { §13. Apurada irregularidade recorrente ou } \\
\text { fragilidade nos procedimentos, } \\
\text { reconhecidas na forma prevista no caput } \\
\text { ou pelos órgãos de controle, os } \\
\text { procedimentos de análise e concessão de } \\
\text { benefícios serão revistos, de modo a } \\
\text { reduzir o risco de fraude e concessão } \\
\text { irregular. }\end{array}$ \\
\hline Sem correspondência. & $\begin{array}{l}\S \text { 14. Para fins do disposto no } \S 8^{\circ} \text {, } \\
\text { preservada a integridade dos dados e o } \\
\text { sigilo eventualmente existente, o INSS: } \\
\text { I - terá acesso a todos os dados } \\
\text { biométricos mantidos e administrados } \\
\text { pelos órgãos públicos federais; e }\end{array}$ \\
\hline
\end{tabular}


II - por meio de convênio, poderá ter acesso aos dados biométricos:

a) da Justiça Eleitoral; e

b) de outros entes federativos.

\section{Penhorabilidade do bem de família}

O artigo 22 modifica a Lei 8.009/1990, que dispõe sobre a impenhorabilidade do bem de família, para incluir, no rol do artigo $3^{\circ}$, o qual traz, taxativamente, a hipóteses nas quais a impenhorabilidade será inoponível em processos de execução de débitos previdenciários. Nesse sentido, a única inclusão operada pela MPv 871/2019 foi a do inciso VIII, pelo qual o bem de família poderá ser penhorado "para cobrança de crédito constituído pela Procuradoria-Geral Federal em decorrência de benefício previdenciário ou assistencial recebido indevidamente por dolo, fraude ou coação, inclusive por terceiro que sabia ou deveria saber da origem ilícita dos recursos".

\section{Regras gerais sobre os benefícios previdenciários}

O artigo 25 trouxe importantes alterações sobre algumas das regras gerais acerca dos benefícios previdenciários, modificando a LBPS nos seguintes dispositivos:

\subsection{Dependentes}

A alteração feita no artigo 16 , com a inclusão do $\S 5^{\circ}$, trouxe uma dificuldade à comprovação do vínculo de união estável e de dependência econômica, já que não são mais suficientes, salvo muito excepcionalmente, as provas testemunhais. A partir da MPv, é necessário que, para a realização de audiência de instrução, a parte autora junte aos autos prova material contemporânea aos fatos. Assim, o pedido de reconhecimento da união estável, se não contar com prova robusta documental, deve ser acompanhado por início de prova material, a ser chancelado por prova testemunhal e/ou por depoimento pessoal, na forma como acontece nos casos de prova de atividade rural, pesqueira e análogas.

\begin{tabular}{|l|l|}
\hline \multicolumn{1}{|c|}{ Redação anterior à MPv 871 } & \multicolumn{1}{|c|}{ Redação dada pela MPv 871 } \\
\hline $\begin{array}{l}\text { Art. 16. São beneficiários do Regime } \\
\text { Geral de Previdência Social, na condição } \\
\text { de dependentes do segurado: }\end{array}$ & $\begin{array}{l}\text { Art. 16. São beneficiários do Regime } \\
\text { Geral de Previdência Social, na condição } \\
\text { de dependentes do segurado: }\end{array}$ \\
\hline Sem correspondência. & $\begin{array}{l}\S 5 \text { A prova de união estável e de } \\
\text { dependência econômica exigem início de } \\
\text { prova material contemporânea dos fatos, }\end{array}$ \\
\hline
\end{tabular}




\begin{tabular}{|l|l|}
\hline & $\begin{array}{l}\text { não admitida a prova exclusivamente } \\
\text { testemunhal, exceto na ocorrência de } \\
\text { motivo de força maior e ou caso fortuito, } \\
\text { conforme disposto no Regulamento. }\end{array}$ \\
\hline
\end{tabular}

\subsection{Regularização post mortem}

$\mathrm{O} \S 7^{\circ}$ do artigo 17 firma a impossibilidade de inscrição post mortem de segurados contribuinte individual e facultativo. Portanto, para esses dois tipos de segurado, a LBPS passou a prever a impossibilidade da regularização do recolhimento de contribuições.

A propósito, em relação ao contribuinte individual, há a Súmula 52/TNU: "para fins de concessão de pensão por morte, é incabível a regularização do recolhimento de contribuições de segurado contribuinte individual posteriormente a seu óbito, exceto quando as contribuições devam ser arrecadadas por empresa tomadora de serviços".

O STJ também tem o entendimento de que é impossível o "recolhimento pelos dependentes, para fins de concessão do benefício de pensão por morte, de contribuições vertidas após o óbito do instituidor, no caso de contribuinte individual" (AgInt no REsp 1410837, Rel. Min. Og Fernandes, 2T, DJe 11/10/2018; AgInt no REsp 1568139, Rel. Min. Regina Helena Costa, 1T, DJe 23/05/2018; AgRg no REsp 1284217, Rel. Min. Marco Aurélio Bellizze, 5T, DJe 04/06/2014).

Para fins de registro, é importante colacionar o entendimento do STJ sobre a regularização post mortem para os segurados em geral, já que o $\S 7^{\circ}$ dá a impressão de que é possível a inscrição após a morte. Assim: "é imprescindível o recolhimento das contribuições respectivas pelo próprio segurado quando em vida para que seus dependentes possam receber o benefício de pensão por morte", de maneira que "não há base legal para uma inscrição post mortem ou para que sejam regularizadas as contribuições pretéritas, não recolhidas em vida" (REsp 1582774, Rel. Min. Herman Benjamin, 2T, DJe 31/05/2016).

Esse entendimento nem o $\$ 7^{\circ}$ se confundem, entretanto, com o disposto na Súmula 416/STJ: "é devida a pensão por morte aos dependentes do segurado que, apesar de ter perdido essa qualidade, preencheu os requisitos legais para a obtenção de aposentadoria até a data do seu óbito".

\begin{tabular}{|l|l|}
\hline \multicolumn{1}{|c|}{ Redação anterior à MPv 871 } & \multicolumn{1}{|c|}{ Redação dada pela MPv 871 } \\
\hline $\begin{array}{l}\text { Art. 17. O Regulamento disciplinará a } \\
\text { forma de inscrição do segurado e dos } \\
\text { dependentes. }\end{array}$ & $\begin{array}{l}\text { Art. 17. O Regulamento disciplinará a } \\
\text { forma de inscrição do segurado e dos } \\
\text { dependentes. }\end{array}$ \\
\hline
\end{tabular}




\subsection{Períodos de carência}

As alterações procedidas nos artigos 25, 26 e 27-A da LBPS foram basicamente duas.

Em primeiro lugar, a carência do auxílio-reclusão, antes inexistente, passa a ser de 24 meses, o que irá, certamente, dificultar bastante a obtenção do benefício. Todavia, como era esperado, servirá para lhe dar uma natureza realmente previdenciária, já que a ausência de período de carência o fazia parecer muito mais um benefício assistencial.

Além disso, a segunda alteração quanto à carência está na perda da qualidade de segurado. Nesses casos, o requerente dos benefícios de auxílio-doença, aposentadoria por invalidez, salário-maternidade e auxílio-reclusão deve contar, a partir da nova data de filiação à Previdência Social, com os períodos integrais de carência: 12 contribuições mensais para os dois primeiros, 10 para o terceiro (nos casos de contribuinte individual, segurado especial ou segurado facultativo) e 24 para o último.

\begin{tabular}{|c|c|}
\hline ão anterior à MPv 871 & Redação dada pela MPv 871 \\
\hline $\begin{array}{l}\text { Art. 25. A concessão das prestações } \\
\text { pecuniárias do Regime Geral de } \\
\text { Previdência Social depende dos seguintes } \\
\text { períodos de carência, ressalvado o } \\
\text { disposto no art. 26: }\end{array}$ & $\begin{array}{l}\text { Art. 25. A concessão das prestações } \\
\text { pecuniárias do Regime Geral de } \\
\text { Previdência Social depende dos seguintes } \\
\text { períodos de carência, ressalvado o } \\
\text { disposto no art. 26: }\end{array}$ \\
\hline $\begin{array}{l}\text { III - salário-maternidade para as seguradas } \\
\text { de que tratam os incisos V e VII do art. } 11 \\
\text { e o art. 13: dez contribuições mensais, } \\
\text { respeitado o disposto no parágrafo único } \\
\text { do art. } 39 \text { desta Lei. }\end{array}$ & $\begin{array}{l}\text { III - salário-maternidade para as seguradas } \\
\text { de que tratam os incisos V e VII do caput } \\
\text { do art. } 11 \text { e o art. 13: dez contribuições } \\
\text { mensais, respeitado o disposto no } \\
\text { parágrafo único do art. } 39 \text {; e }\end{array}$ \\
\hline Sem corre & $\begin{array}{l}\text { IV - auxílio-reclusão: vinte e quatro } \\
\text { contribuições mensais. }\end{array}$ \\
\hline $\begin{array}{l}\text { Art. } 26 . \\
\text { concessão }\end{array}$ & $\begin{array}{l}\text { Art. 26. Independe de carência a } \\
\text { concessão das seguintes prestações: }\end{array}$ \\
\hline $\begin{array}{l}\text { I - pens } \\
\text { salário-fe }\end{array}$ & morte, salário-família e \\
\hline $\begin{array}{l}\text { Art. 27-A. No caso de perda da qualidade } \\
\text { de segurado, para efeito de carência para a } \\
\text { concessão dos benefícios de que trata esta } \\
\text { Lei, o segurado deverá contar, a partir da } \\
\text { nova filiação à Previdência Social, com } \\
\text { metade dos períodos previstos nos incisos } \\
\text { I e III do caput do art. } 25 \text { desta Lei. }\end{array}$ & $\begin{array}{l}\text { Art. 27-A. Na hipótese de perda da } \\
\text { qualidade de segurado, para fins da } \\
\text { concessão dos benefícios de auxílio- } \\
\text { doença, de aposentadoria por invalidez, de } \\
\text { salário-maternidade e de auxílio-reclusão, } \\
\text { o segurado deverá contar, a partir da data } \\
\text { da nova filiação à Previdência Social, com }\end{array}$ \\
\hline
\end{tabular}




\subsection{Prazo decadencial}

A MPv trouxe importante alteração quanto ao prazo decadencial, que recupera um entendimento antigo da TNU, firmado na Súmula 64, atualmente cancelada, cujo teor era o seguinte: "o direito à revisão do ato de indeferimento de benefício previdenciário ou assistencial sujeita-se ao prazo decadencial de dez anos". Com o novo texto do artigo 103 da LBPS, passou-se novamente a aplicar o prazo decadencial não apenas aos pedidos de revisão de benefícios, mas também aos pedidos de concessão baseados em indeferimentos administrativos. Essa novidade teve como consequência lógica a revogação do artigo 79 da LBPS, que previa a inaplicabilidade do disposto no artigo 103 da LBPS ao pensionista menor, incapaz ou ausente.

\begin{tabular}{|c|c|}
\hline Redação anterior à MPv 871 & Redação dada pela MPv 871 \\
\hline $\begin{array}{l}\text { Art. 103. É de dez anos o prazo de } \\
\text { decadência de todo e qualquer direito ou } \\
\text { ação do segurado ou beneficiário para a } \\
\text { revisão do ato de concessão de benefício, } \\
\text { a contar do dia primeiro do mês seguinte } \\
\text { ao do recebimento da primeira prestação } \\
\text { ou, quando for o caso, do dia em que tomar } \\
\text { conhecimento da decisão indeferitória } \\
\text { definitiva no âmbito administrativo. }\end{array}$ & $\begin{array}{l}\text { Art. } 103 \text {. O prazo de decadência do direito } \\
\text { ou da ação do segurado ou beneficiário } \\
\text { para a revisão do ato de concessão, } \\
\text { indeferimento, cancelamento ou cessação } \\
\text { de benefício, do ato de deferimento, } \\
\text { indeferimento ou não concessão de } \\
\text { revisão de benefício é de dez anos, } \\
\text { contado: } \\
\text { I - do dia primeiro do mês subsequente ao } \\
\text { do recebimento da primeira prestação ou } \\
\text { da data em que a prestação deveria ter sido } \\
\text { paga com o valor revisto; ou } \\
\text { II - do dia em que o segurado tomar } \\
\text { conhecimento da decisão } \\
\text { indeferimento, cancelamento ou cessação } \\
\text { do seu pedido de benefício ou da decisão } \\
\text { de deferimento ou indeferimento de } \\
\text { revisão de benefício, no âmbito } \\
\text { administrativo. }\end{array}$ \\
\hline
\end{tabular}

\subsection{Descontos de benefícios}

A LBPS estabelece em seu artigo 115 em quais situações os benefícios podem sofrer descontos. A modificação trazida pela MPv incidiu sobre a possibilidade de que haja desconto quando o benefício for pago indevidamente ou além do devido. A nova redação manteve a inscrição do débito em dívida ativa pela Procuradoria-Geral Federal, mas inseriu a possibilidade de cessação do benefício pela revogação de decisão, nos 
termos da Lei de Execução Fiscal 6.830/1980 (LEF), podendo ser incluído o terceiro beneficiado que sabia ou deveria saber sobre a irregularidade do pagamento, desde que devidamente identificado em procedimento administrativo de responsabilização, segundo firmado em regulamento.

As alterações e inclusões estão a seguir reproduzidas:

\begin{tabular}{|c|c|}
\hline Redação anterior à MPv 871 & Redação dada pela MPv 871 \\
\hline $\begin{array}{l}\text { Art. 115. Podem ser descontados dos } \\
\text { benefícios: } \\
\text { II - pagamento de benefício além do } \\
\text { devido; }\end{array}$ & $\begin{array}{l}\text { Art. } 115 \text {. Podem ser descontados dos } \\
\text { benefícios: } \\
\text { II - pagamento administrativo ou judicial } \\
\text { de benefício previdenciário ou assistencial } \\
\text { indevido, ou além do devido, inclusive na } \\
\text { hipótese de cessação do benefício pela } \\
\text { revogação de decisão judicial, nos termos } \\
\text { do disposto no Regulamento. }\end{array}$ \\
\hline $\begin{array}{l}\text { § } 3^{\text {o }} \text { Serão inscritos em dívida ativa pela } \\
\text { Procuradoria-Geral Federal os créditos } \\
\text { constituídos pelo INSS em razão de } \\
\text { benefício previdenciário ou assistencial } \\
\text { pago indevidamente ou além do devido, } \\
\text { hipótese em que se aplica o disposto } \\
\text { na Lei } \mathrm{n}^{\mathrm{o}} 6.830 \text {, de } 22 \text { de setembro de } \\
\text { 1980, para a execução judicial. }\end{array}$ & $\begin{array}{l}\text { § } 3^{\circ} \text { Serão inscritos em dívida ativa pela } \\
\text { Procuradoria-Geral Federal os créditos } \\
\text { constituídos pelo INSS em decorrência de } \\
\text { benefício previdenciário ou assistencial } \\
\text { pago indevidamente ou além do devido, } \\
\text { inclusive na hipótese de cessação do } \\
\text { benefício pela revogação de decisão } \\
\text { judicial, nos termos do disposto na Lei no } \\
\text { 6.830, de } 22 \text { de setembro de 1980, para a } \\
\text { execução judicial. }\end{array}$ \\
\hline Sem correspondências. & $\begin{array}{l}\S 4^{\circ} \text { Será objeto de inscrição em dívida } \\
\text { ativa, para os fins do disposto no } \S 3^{\circ} \text {, em } \\
\text { conjunto ou separadamente, o terceiro } \\
\text { beneficiado que sabia ou deveria saber da } \\
\text { origem do benefício pago indevidamente } \\
\text { em razão de fraude, dolo ou coação, desde } \\
\text { que devidamente identificado em } \\
\text { procedimento administrativo de } \\
\text { responsabilização. } \\
\S 5^{\circ} \text { O procedimento de que trata o } \S 4^{\circ} \\
\text { será disciplinado em regulamento, nos } \\
\text { termos do disposto na Lei no } 9.784 \text {, de } 29 \\
\text { de janeiro de } 1999 \text {, e no art. } 27 \text { do } \\
\text { Decreto-Lei no } 4.657 \text {, de } 4 \text { de setembro de } \\
1942 \text {. } \\
\S 6^{\circ} \text { A alienação ou a oneração de bens ou } \\
\text { rendas, ou o início de um desses } \\
\text { processos, por beneficiário ou } \\
\text { responsabilizado inscrito em dívida ativa, } \\
\text { nas hipóteses previstas nos } \S 3^{\circ} \text { e } \S 4^{\circ} \text {, será } \\
\text { presumida fraudulenta e caberá ao } \\
\text { regulamento disciplinar a forma de }\end{array}$ \\
\hline
\end{tabular}




\begin{tabular}{|l|l|}
\hline & atribuir publicidade aos débitos dessa \\
& natureza. \\
& $\S 7^{\circ} \mathrm{Na}$ hipótese prevista no inciso V do \\
& caput, a autorização do desconto deverá \\
& ser revalidada anualmente nos termos do \\
& disposto no Regulamento. \\
\hline
\end{tabular}

\subsection{Exames médicos posteriores à concessão do benefício}

O artigo 101, caput, da LBPS estabelece que os beneficiários de auxílio-doença ou de aposentadoria por invalidez e que os pensionistas inválidos têm a obrigação de se submeter, sob pena de suspensão do benefício, a exame médico a cargo da Previdência Social, processo de reabilitação profissional por ela prescrito e custeado, e tratamento dispensado gratuitamente, salvo cirurgia e transfusão de sangue, que são facultativos.

Em relação ao aposentado por invalidez e ao pensionista inválido, desde que não tenham retornado à atividade, o $\S 1^{\circ}$ do artigo 101 da LBPS reconhece a sua isenção do exame. Antes da MPv 871, havia dois casos de isenção: I - depois de completar 55 ou mais anos de idade, desde que decorridos 15 anos da concessão da aposentadoria ou do auxílio-doença originário; ou II - depois de completar 60 anos de idade. Com a MPv 871, a primeira hipótese foi extinta, remanescendo apenas a segunda.

\begin{tabular}{|c|c|}
\hline Redação anterior à MPv 871 & Redação dada pela MPv 871 \\
\hline $\begin{array}{l}\text { Art. 101. (...) } \\
\S \text { 1 } \text { O O aposentado por invalidez e o } \\
\text { pensionista inválido que não tenham } \\
\text { retornado à atividade estarão isentos do } \\
\text { exame de que trata o caput deste artigo: } \\
\text { I - após completarem cinquenta e cinco } \\
\text { anos ou mais de idade e quando decorridos } \\
\text { quinze anos da data da concessão da } \\
\text { aposentadoria por invalidez ou do auxílio- } \\
\text { doença que a precedeu; (...) }\end{array}$ & $\begin{array}{l}\text { Art. 101. (...) } \\
\S 1^{\circ} \text { O aposentado por invalidez e o } \\
\text { pensionista inválido que não tenham } \\
\text { retornado à atividade estarão isentos do } \\
\text { exame de que trata o caput deste artigo: } \\
\text { I - REVOGADO. }\end{array}$ \\
\hline
\end{tabular}

\section{Aposentadoria por tempo de contribuição}

A nova redação do $\S 3^{\circ}$ do artigo 55 da LBPS, embora tenha mantido a antiga nomenclatura (tempo de serviço), especificou que a comprovação do tempo não pode se basear exclusivamente em prova testemunhal, salvo casos excepcionalíssimos (força maior ou caso fortuito), devendo o requerente anexar ao seu pedido não apenas prova material, mas prova material contemporânea aos fatos que pretende comprovar. 
Em relação ao artigo 96 da LPBS, foram incluídos dispositivos que estabeleceram restrições à emissão de Certidão de Tempo de Contribuição (CTC). A partir da MPv, é necessário para a emissão de CTC com registro exclusivo do tempo que haja prova da contribuição efetiva, salvo em dois casos: (i) se for segurado empregado, empregado doméstico ou trabalhador avulso; e (ii) se o tempo for anterior à edição da EC 20/1998, quando o tempo de serviço tiver sido equiparado por lei a tempo de contribuição.

Além disso, nos casos de ex servidor, a CTC somente poderá ser emitida por Regime Próprio de Previdência Social (RPPS). Também em relação ao RPPS, o artigo 96 da LBPS fixou a proibição de contagem recíproca de contribuição do RGPS por RPPS sem a emissão da CTC correspondente, mesmo que o tempo no RGPS tenha sido prestado pelo servidor ao próprio ente instituição. Ademais, fica proibida a desaverbação do tempo em RPPS quando o tempo tiver gerado a concessão de vantagens remuneratórias ao servidor em atividade.

Eis as alterações:

\begin{tabular}{|c|c|}
\hline Redação anterior à MPv 871 & Redação dada pela MPv 871 \\
\hline $\begin{array}{l}\text { Art. } 55 \text { (...). } \\
\S 3^{\circ} \text { A comprovação do tempo de serviço } \\
\text { para os efeitos desta Lei, inclusive } \\
\text { mediante justificação administrativa ou } \\
\text { judicial, conforme o disposto no art. } 108 \text {, } \\
\text { só produzirá efeito quando baseada em } \\
\text { início de prova material, não sendo } \\
\text { admitida prova exclusivamente } \\
\text { testemunhal, salvo na ocorrência de } \\
\text { motivo de força maior ou caso fortuito, } \\
\text { conforme disposto no Regulamento. }\end{array}$ & $\begin{array}{l}\text { Art. } 55 \text { (...) } \\
\S 3^{\circ} \text { A comprovação do tempo de serviço } \\
\text { para fins do disposto nesta Lei, inclusive } \\
\text { mediante justificativa administrativa ou } \\
\text { judicial, observado o disposto no art. } 108 \text {, } \\
\text { só produzirá efeito quando for baseada em } \\
\text { início de prova material contemporânea } \\
\text { dos fatos, não admitida a prova } \\
\text { exclusivamente testemunhal, exceto na } \\
\text { ocorrência de motivo de força maior ou } \\
\text { caso fortuito, na forma prevista no } \\
\text { Regulamento. }\end{array}$ \\
\hline $\begin{array}{l}\text { Art. } 96 . \text { (...) } \\
\text { Sem correspondência. }\end{array}$ & $\begin{array}{l}\text { Art. 96. (...) } \\
\text { V - é vedada a emissão de Certidão de } \\
\text { Tempo de Contribuição - CTC com o } \\
\text { registro exclusivo de tempo de serviço, } \\
\text { sem a comprovação de contribuição } \\
\text { efetiva, exceto para o segurado } \\
\text { empregado, empregado doméstico e } \\
\text { trabalhador avulso; }\end{array}$ \\
\hline Sem correspondência. & $\begin{array}{l}\text { VI - a CTC somente poderá ser emitida } \\
\text { por regime próprio de previdência social } \\
\text { para ex servidor; }\end{array}$ \\
\hline Sem correspondência. & $\begin{array}{l}\text { VII - é vedada a contagem recíproca de } \\
\text { tempo de contribuição do RGPS por } \\
\text { regime próprio de previdência social sem } \\
\text { a emissão da CTC correspondente, ainda }\end{array}$ \\
\hline
\end{tabular}




\begin{tabular}{|l|l|}
\hline Sem correspondência. & $\begin{array}{l}\text { que o tempo de contribuição RGPS tenha } \\
\text { sido prestado pelo servidor público ao } \\
\text { próprio ente instituidor; e }\end{array}$ \\
\hline Sem correspondência. & $\begin{array}{l}\text { VIII - é vedada a desaverbação de tempo } \\
\text { em regime próprio de previdência social } \\
\text { quando o tempo averbado tenha gerado a } \\
\text { concessão de vantagens remuneratórias ao } \\
\text { servidor público em atividade. }\end{array}$ \\
\hline $\begin{array}{l}\text { Parágrafo único. O disposto no inciso V } \\
\text { do caput não se aplica ao tempo de serviço } \\
\text { anterior à edição da Emenda } \\
\text { Constitucional no 20, de 1998, que tenha } \\
\text { sido equiparado por lei a tempo de } \\
\text { contribuição. }\end{array}$ \\
\hline
\end{tabular}

\section{Aposentadoria por idade - segurado especial}

As alterações realizadas nos dispositivos da subseção sobre a renda mensal dos benefícios, da LBPS, estenderam o uso do CNIS para os segurados especiais, mantendo o cadastro e atualizando-o anualmente, com vencimento sempre no dia 30/06, podendo as atualizações serem feitas em até cinco anos, sempre contando dessa data. A autarquia previdenciária utilizará, então, esse cadastro para fins de comprovação do exercício da atividade e da condição do segurado especial e do respectivo grupo familiar, de maneira que, a partir de 01/01/2020, a comprovação da condição de segurado especial e também do exercício de atividade rural será feita exclusivamente com informações do CNIS, as quais serão nele incluídas por meio de auto declaração, a ser confirmada por entidades públicas credenciadas, na forma do artigo 13 da Lei 12.188/2010, bem como por outros órgãos públicos, na forma do Regulamento da Previdencia Social (RPS).

O $\S 2^{\circ}$ do artigo 38-B da LBPS prevê que, em relação ao período anterior ao dia 01/01/2020, o tempo de atividade rural deverá ser comprovado pelo segurado especial por meio de autodeclaração ratificada por entidade públicas credenciadas, na forma do artigo 13 da Lei 12.188/2010, e por outros órgãos públicos, conforme o RPS. A ratificação prevista no dispositivo será exigida, de acordo com o artigo 32 da MPv, apenas após o prazo de 60 dias, contado da data da publicação da MPv, tempo durante o qual o INSS aceitará a autodeclaração do segurado, independentemente da ratificação e sem prejuízo da exigência de apresentação dos documentos elencados no artigo 106 da LBPS.

\begin{tabular}{|c|c|}
\hline terior à MP & Redaç \\
\hline $\begin{array}{l}\text { Art. 38-A. O Ministério da Previdência } \\
\text { Social desenvolverá programa de }\end{array}$ & $\begin{array}{l}\text { Art. 38-A. O Ministério da Economia } \\
\text { manterá sistema de cadastro dos }\end{array}$ \\
\hline
\end{tabular}


cadastramento dos segurados especiais, observado o disposto nos $\S \S 4^{\circ}$ e $5^{\circ}$ do art. 17 desta Lei, podendo para tanto firmar convênio com órgãos federais, estaduais ou do Distrito Federal e dos Municípios, bem como com entidades de classe, em especial as respectivas confederações ou federações.

$\S 1^{\circ}$. O programa de que trata o caput deste artigo deverá prever a manutenção e a atualização anual do cadastro e conter todas as informações necessárias à caracterização da condição de segurado especial.

Sem correspondência. segurados especiais no Cadastro Nacional de Informações Sociais - CNIS, observado o disposto nos $\S 4^{\circ}$ e $\S 5^{\circ}$ do art. 17, e poderá firmar acordo de cooperação com o Ministério da Agricultura, Pecuária e Abastecimento e com outros órgãos da administração pública federal, estadual, distrital e municipal para a manutenção e a gestão do sistema de cadastro.

$\S 1^{\circ} \mathrm{O}$ sistema de que trata o caput preverá a manutenção e a atualização anual do cadastro e conterá as informações necessárias à caracterização da condição de segurado especial, nos termos do disposto no Regulamento.

$\S 3^{0}$ O INSS, no ato de habilitação ou de concessão de benefício, deverá verificar a condição de segurado especial e, se for o caso, o pagamento da contribuição previdenciária, nos termos da Lei $\mathrm{n}^{0} 8.212$, de 24 de julho de 1991, considerando, dentre outros, o que consta do Cadastro Nacional de Informações Sociais (CNIS) de que trata o art. 29-A desta Lei.

Sem correspondência. $\S 4^{\circ} \mathrm{A}$ atualização anual de que trata o $\S 1^{\circ}$ será feita até 30 de junho do ano subsequente.

Sem correspondência.

$\S 5^{\circ}$ Decorrido o prazo de que trata o $\S 4^{\circ}$, o segurado especial só poderá computar o período de trabalho rural se efetuado em época própria o recolhimento na forma prevista no art. 25 da Lei $n^{\circ} 8.212$, de 1991.

Sem correspondência.

$\S 6^{\circ}$ É vedada a atualização de que trata o $\S 1^{\circ}$ após o prazo de cinco anos, contado da data estabelecida no $\S 4^{\circ}$.

Sem correspondência. Art. 38-B. (...)

$\S 1^{\circ} \mathrm{A}$ partir de $1^{\circ}$ de janeiro de 2020 , a comprovação da condição e do exercício da atividade rural do segurado especial ocorrerá exclusivamente pelas informações constantes do cadastro a que se refere $\mathrm{o}$ art. 38-A.

Sem correspondência. de 2020, o segurado especial comprovará o tempo de exercício da atividade rural por meio de autodeclaração ratificada por entidades públicas credenciadas, nos termos do disposto no art. 13 da Lei $\mathrm{n}^{\circ}$ 


\begin{tabular}{|c|c|}
\hline & $\begin{array}{l}12.188 \text {, de } 11 \text { de janeiro de } 2010 \text {, e por } \\
\text { outros órgãos públicos, na forma prevista } \\
\text { no Regulamento. }\end{array}$ \\
\hline Sem correspondência. & $\begin{array}{l}\S 3^{\circ} \text { Na hipótese de haver divergência de } \\
\text { informações, para fins de reconhecimento } \\
\text { de direito com vistas à concessão de } \\
\text { benefício, o INSS poderá exigir a } \\
\text { apresentação dos documentos referidos no } \\
\text { art. } 106 \text {. }\end{array}$ \\
\hline $\begin{array}{l}\text { Art. 106. A comprovação do exercício de } \\
\text { atividade rural será feita, } \\
\text { alternativamente, por meio de: } \\
\text { III - declaração fundamentada de sindicato } \\
\text { que represente o trabalhador rural ou, } \\
\text { quando for o caso, de sindicato ou colônia } \\
\text { de pescadores, desde que homologada } \\
\text { pelo Instituto Nacional do Seguro Social - } \\
\text { INSS; }\end{array}$ & $\begin{array}{l}\text { Art. 106. A comprovação do exercício de } \\
\text { atividade rural será feita, } \\
\text { complementarmente à declaração de que } \\
\text { trata o art. 38-B, por meio de: } \\
\text { III - REVOGADO. }\end{array}$ \\
\hline $\begin{array}{l}\text { IV - comprovante de cadastro do Instituto } \\
\text { Nacional de Colonização e Reforma } \\
\text { Agrária - INCRA, no caso de produtores } \\
\text { em regime de economia familiar; }\end{array}$ & $\begin{array}{l}\text { IV - Declaração de Aptidão ao Programa } \\
\text { Nacional de Fortalecimento da } \\
\text { Agricultura Familiar, de que trata o inciso } \\
\text { II do caput do art. } 2^{\circ} \text { da Lei no } 12.188 \text {, de } \\
11 \text { de janeiro de } 2010 \text {, ou por documento } \\
\text { que a substitua, emitidas apenas por } \\
\text { instituições ou organizações públicas; }\end{array}$ \\
\hline
\end{tabular}

\section{Auxílio-doença}

A MPv excluiu o pagamento do auxílio-doença a segurados reclusos em regime fechado, passando a prever que o benefício será suspenso, no caso de segurados que já o recebam e sejam presos em tal regime. A suspensão do eventual benefício durará 60 dias, contados da data em que o recolhimento ocorrer, de maneira que, se o segurado for posto em liberdade antes do decurso do prazo, o benefício será restabelecido a partir da data da soltura, mas se ficar preso por mais de 60 dias, o benefício será cessado.

As inclusões estão a seguir reproduzidas:

\begin{tabular}{|c|c|}
\hline Redação anterior à MPv 871 & Redação dada pela MPv 871 \\
\hline $\begin{array}{l}\text { Art. 59. (...) } \\
\text { Parágrafo único. Não será devido auxílio- } \\
\text { doença ao segurado que se filiar ao } \\
\text { Regime Geral de Previdência Social já } \\
\text { portador da doença ou da lesão invocada } \\
\text { como causa para o benefício, salvo } \\
\text { quando a incapacidade sobrevier por } \\
\text { motivo de progressão ou agravamento } \\
\text { dessa doença ou lesão. }\end{array}$ & $\begin{array}{l}\text { Art. 59. (...) } \\
\S 1^{\circ} \text { Não será devido o auxílio-doença ao } \\
\text { segurado que se filiar ao Regime Geral de } \\
\text { Previdência Social já portador da doença } \\
\text { ou da lesão invocada como causa para o } \\
\text { benefício, exceto quando a incapacidade } \\
\text { sobrevier por motivo de progressão ou } \\
\text { agravamento da doença ou da lesão. }\end{array}$ \\
\hline
\end{tabular}




\begin{tabular}{|l|l|}
\hline Sem correspondência. & $\begin{array}{l}\S 2^{\circ} \text { Não será devido o auxílio-doença para } \\
\text { o segurado recluso em regime fechado. }\end{array}$ \\
\hline Sem correspondência. & $\begin{array}{l}\S 3^{\circ} \text { O segurado em gozo de auxílio- } \\
\text { doença na data do recolhimento à prisão } \\
\text { terá o benefício suspenso. }\end{array}$ \\
\hline Sem correspondência. & $\begin{array}{l}\S 4^{\circ} \text { A suspensão prevista no } 3^{\circ} \text { será de } \\
\text { até sessenta dias, contados da data do } \\
\text { recolhimento à prisão, cessado o benefício } \\
\text { após o referido prazo. }\end{array}$ \\
\hline Sem correspondência. & $\begin{array}{l}\S 5^{\circ} \text { Na hipótese de o segurado ser } \\
\text { colocado em liberdade antes do prazo } \\
\text { previsto no § } 4^{\circ} \text { o benefício será } \\
\text { restabelecido a partir da data da soltura. }\end{array}$ \\
\hline
\end{tabular}

\section{Salário-maternidade}

A alteração promovida em relação ao salário-maternidade diz respeito ao prazo decadencial para a formulação de seu requerimento. Trata-se de inovação na legislação sobre o benefício. A partir de agora, ocorrido o fato gerador (parto ou adoção), salvo na hipótese de força maior ou caso fortuito, a parte requerente tem 180 dias para pleitear o pagamento do salário-maternidade, como prevê o novo artigo 71-D a seguir transcrito:

\begin{tabular}{|l|l|}
\hline \multicolumn{1}{|c|}{ Redação anterior à MPv 871 } & \multicolumn{1}{|c|}{ Redação dada pela MPv 871 } \\
\hline Sem correspondência. & Art. 71-D. O direito ao salário- \\
& maternidade decairá se não for requerido \\
em até cento e oitenta dias da ocorrência & do parto ou da adoção, exceto na \\
ocorrência de motivo de força maior e ou \\
caso fortuito, conforme disposto no \\
Regulamento.
\end{tabular}

\section{Pensão por morte}

A MPv 871/2019 traz importantes alterações na regulamentação do benefício previdenciário, tanto em dispositivos do Estatuto dos Servidores Públicos Civis Federais, Lei 8.112/1990, quanto em dispositivos da LBPS.

\subsection{Pensão por morte estatutária}

A pensão por morte estatutária não poderá mais ser requerida a qualquer tempo, é necessário ao dependente observar os seguintes prazos, caso queira receber os valores a partir da data do óbito (fato gerador) do instituidor: (a) até 180 dias, após a data do óbito 
(fato gerador), se o requerimento for feito por filhos absolutamente incapazes (menores de 16 anos); ou (b) até 90 dias, após a data do óbito, para todos os demais dependentes.

Se o requerimento não for feito nos prazos acima, o benefício será devido a partir da data de entrada do requerimento (DER), salvo no caso de morte presumida, quando o dies a quo será a data da decisão judicial.

Na hipótese de haver mais de um dependente habilitável, a concessão não poderá ser postergada para que todos se habitem. Essa previsão se assemelha a outra contida na LBPS, de modo que, aqui, os benefícios se equivalem, quanto à regulamentação - o que, de modo geral, foi proporcionado pela MPv. Assim, o dependente retardatário só terá direito aos valores a partir da concessão do benefício.

É bastante interessante, nesse passo, o $§ 2^{\circ}$ do artigo 229, o qual restringe a tutela de urgência, de modo que o dependente retardatário, ao requerer a concessão liminar, caso ela seja deferida, não receberá, os valores da quota que lhe diria respeito, os quais ficarão aprovisionados até o trânsito em julgado da decisão judicial. Os valores, na forma do $\S 3^{\circ}$, enquanto retidos serão corrigidos pelos índices legais de reajuste. Se reconhecido o direito ao dependente retardatário, assim que transitada em julgado a decisão, o valor lhe será destinado. Todavia, se julgado improcedente o seu pedido, o valor retido será pago proporcionalmente aos demais dependentes.

O $\S 5^{\circ}$ do artigo 222 da Lei 8.112/1990 traz a previsão de que se houver pensão alimentícia temporária, judicialmente concedida, decorrente de casamento ou de união estável, a pensão por morte será devida pelo prazo que faltar na data do óbito, a não ser que haja a ocorrência de alguma hipótese de cancelamento. $\mathrm{O}$ dispositivo não esclarece, mas tudo indica que o valor da pensão será o mesmo dos alimentos, normalmente fixado em um percentual da remuneração ou da aposentadoria recebida pelo alimentante.

O quadro comparativo abaixo demonstra com clareza quais as modificações nas condições de concessão do benefício de pensão por morte a dependentes de servidores falecidos:

\begin{tabular}{|l|l|}
\hline \multicolumn{1}{|c|}{ Redação anterior à MPv 871 } & \multicolumn{1}{|c|}{ Redação dada pela MPv 871 } \\
\hline Art. 215. Por morte do servidor, os & $\begin{array}{l}\text { Art. 215. Por morte do servidor, os } \\
\text { dependentes, nas hipóteses legais, fazem } \\
\text { dependentes, nas hipóteses legais, fazem }\end{array}$ \\
jus à pensão a partir da data de óbito, & jus à pensão por morte, observados os \\
observado o limite estabelecido no inciso & $\begin{array}{l}\text { limites estabelecidos no inciso XI do } \\
\text { XI do caput do art. } 37 \text { da Constituição } \\
\text { caput do art. 37 da Constituição e no art. } \\
\text { Federal e no art. } 2^{\circ} \text { da Lei n }{ }^{\circ} 10.887, \text { de } 18 \\
2^{\circ} \text { da Lei no } 10.887 \text {, de } 18 \text { de junho de } \\
\text { de junho de } 2004 .\end{array}$ \\
\hline
\end{tabular}




\begin{tabular}{|c|c|}
\hline $\begin{array}{l}\text { Art. 219. A pensão poderá ser requerida a } \\
\text { qualquer tempo, prescrevendo tão- } \\
\text { somente as prestações exigíveis há mais } \\
\text { de } 5 \text { (cinco) anos. }\end{array}$ & $\begin{array}{l}\text { Art. 219. A pensão por morte será devida } \\
\text { ao conjunto dos dependentes do segurado } \\
\text { que falecer, aposentado ou não, a contar } \\
\text { da data: }\end{array}$ \\
\hline Sem correspondência. & $\begin{array}{l}\text { I - do óbito, quando requerida em até cento } \\
\text { e oitenta dias após o óbito, para os filhos } \\
\text { menores de dezesseis anos, ou em até } \\
\text { noventa dias após o óbito, para os demais } \\
\text { dependentes; }\end{array}$ \\
\hline Sem correspondência. & $\begin{array}{l}\text { II - do requerimento, quando requerida } \\
\text { após o prazo previsto no inciso I; ou }\end{array}$ \\
\hline Sem correspondência. & $\begin{array}{l}\text { III - da decisão judicial, na hipótese de } \\
\text { morte presumida. }\end{array}$ \\
\hline Sem correspondência. & $\begin{array}{l}\S 1^{\circ} \text { A concessão da pensão por morte não } \\
\text { será protelada pela falta de habilitação de } \\
\text { outro possível dependente e a habilitação } \\
\text { posterior que importe em exclusão ou } \\
\text { inclusão de dependente só produzirá efeito } \\
\text { a partir da data da publicação da portaria } \\
\text { de concessão da pensão ao dependente } \\
\text { habilitado. }\end{array}$ \\
\hline Sem correspondência. & $\begin{array}{l}\S 2^{\circ} \text { Ajuizada a ação judicial para } \\
\text { reconhecimento da condição de } \\
\text { dependente, este poderá requerer a sua } \\
\text { habilitação provisória ao benefício de } \\
\text { pensão por morte, exclusivamente para } \\
\text { fins de rateio dos valores com outros } \\
\text { dependentes, vedado o pagamento da } \\
\text { respectiva cota até o trânsito em julgado } \\
\text { da decisão judicial que reconhecer a } \\
\text { qualidade de dependente do autor da ação. }\end{array}$ \\
\hline Sem correspondência. & $\begin{array}{l}\S 3^{\circ} \text { Julgada improcedente a ação prevista } \\
\text { no } \S 2^{\circ} \text {, o valor retido será corrigido pelos } \\
\text { índices legais de reajustamento e será } \\
\text { pago de forma proporcional aos demais } \\
\text { dependentes, de acordo com as suas cotas } \\
\text { e o tempo de duração de seus benefícios. }\end{array}$ \\
\hline Sem correspondência. & $\begin{array}{l}\text { Art. } 222 .(\ldots) \\
\S 5^{\circ} \text { Na hipótese de o servidor falecido } \\
\text { estar, na data de seu falecimento, obrigado } \\
\text { por determinação judicial a pagar } \\
\text { alimentos temporários a ex-cônjuge, ex- } \\
\text { companheiro ou ex companheira, a pensão } \\
\text { por morte será devida pelo prazo } \\
\text { remanescente na data do óbito, caso não } \\
\text { incida outra hipótese de cancelamento } \\
\text { anterior do benefício. }\end{array}$ \\
\hline Sem correspondência. & $\begin{array}{l}\S 6^{\circ} \text { O beneficiário que não atender à } \\
\text { convocação de que trata o } \S 1^{\circ} \text { terá o } \\
\text { benefício suspenso. }\end{array}$ \\
\hline
\end{tabular}




\subsection{Pensão por morte previdenciária}

O primeiro comentário que cabe aqui fazer diz respeito ao $\S 3^{\circ}$ do artigo 74 da LBPS. O dispositivo, incluído pela MPv, não tem aplicabilidade alguma, salvo se esta for convertida em lei e ele mantido. É que o artigo 34, II, estabeleceu um vacatio legis de 120 dias para essa alteração, especificamente. Todavia, como se pode observar, da leitura do artigo 62 da CRFB/1988, o prazo máximo de vigência de uma MPv é de 120 dias. Além disso, é interessante observar que esse mesmo dispositivo foi incluído na Lei 8.112/1990 (artigo 219, § $2^{\circ}$ ), não tendo sofrido essa restrição de vacância.

Outra observação importante, ainda relativa ao $\S 3^{\circ}$, é a aplicabilidade imediata do $\S 4^{\circ}$, que ficou prejudicada em face do artigo 34 , II. Isso porque a retenção da quota do dependente retardatário é determinada pelo artigo sujeito à vacância máxima da MPv.

Quanto às demais alterações promovidas, merece destaque a inclusão de prazo para os filhos menores absolutamente incapazes requererem o benefício. Aqui, como na Lei 8.112/1990, os menores impúberes podiam requerer o benefício a qualquer tempo, com base na regra geral de direito civil de que não correr prescrição nem decadência contra os absolutamente incapazes (artigos 198, I e 208, ambos do Código Civil). Logo, para os óbitos ocorridos entre 18/01/2019 e 17/05/2019, salvo conversão da MPv, o prazo para requerer o benefício é de 180 dias para os menores impúberes.

Essa novidade teve como consequência lógica a revogação do artigo 79 da LBPS, que previa a inaplicabilidade do disposto no artigo 103 da LBPS ao pensionista menor, incapaz ou ausente.

Por fim, o $\S 3^{\circ}$ do artigo 76 da LBPS traz, a exemplo do $\S 5^{\circ}$ do artigo 222 da Lei 8.112/1990, a previsão de que se houver pensão alimentícia temporária, judicialmente concedida, decorrente de casamento ou de união estável, a pensão por morte será devida pelo prazo que faltar na data do óbito, a não ser que haja a ocorrência de alguma hipótese de cancelamento. O dispositivo não esclarece, mas tudo indica que o valor da pensão será o mesmo dos alimentos, normalmente fixado em um percentual da remuneração ou da aposentadoria recebida pelo alimentante.

Eis as novidades, em comparação com a redação anterior:

\section{Redação anterior à MPv 871}

Art. 74. A pensão por morte será devida ao conjunto dos dependentes do segurado

\section{Redação dada pela MPv 871}

Art. 74. A pensão por morte será devida ao conjunto dos dependentes do segurado 


\begin{tabular}{|c|c|}
\hline $\begin{array}{l}\text { que falecer, aposentado ou não, a contar } \\
\text { da data: } \\
\text { I - do óbito, quando requerida até noventa } \\
\text { dias depois deste; }\end{array}$ & $\begin{array}{l}\text { que falecer, aposentado ou não, a contar } \\
\text { da data: } \\
\text { I - do óbito, quando requerida em até cento } \\
\text { e oitenta dias após o óbito, para os filhos } \\
\text { menores de dezesseis anos, ou em até } \\
\text { noventa dias após o óbito, para os demais } \\
\text { dependentes }\end{array}$ \\
\hline Sem correspondência. & $\begin{array}{l}\S 3^{\circ} \text { Ajuizada a ação judicial para } \\
\text { reconhecimento da condição de } \\
\text { dependente, este poderá requerer a sua } \\
\text { habilitação provisória ao benefício de } \\
\text { pensão por morte, exclusivamente para } \\
\text { fins de rateio dos valores com outros } \\
\text { dependentes, vedado o pagamento da } \\
\text { respectiva cota até o trânsito em julgado } \\
\text { da decisão judicial que reconhecer a } \\
\text { qualidade de dependente do autor da ação. }\end{array}$ \\
\hline Sem correspondência. & $\begin{array}{l}\S 4^{\circ} \text { Julgada improcedente a ação prevista } \\
\text { no } \S 3^{\circ} \text {, o valor retido, corrigido pelos } \\
\text { índices legais de reajustamento, será pago } \\
\text { de forma proporcional aos demais } \\
\text { dependentes, de acordo com as suas cotas } \\
\text { e o tempo de duração de seus benefícios. }\end{array}$ \\
\hline Sem correspondência. & $\begin{array}{l}\text { Art. } 76 .(\ldots) \\
\S 3^{\circ} \text { Na hipótese de o segurado falecido } \\
\text { estar, na data de seu falecimento, obrigado } \\
\text { por determinação judicial a pagar } \\
\text { alimentos temporários a ex-cônjuge, ex- } \\
\text { companheiro ou ex companheira, a pensão } \\
\text { por morte será devida pelo prazo } \\
\text { remanescente na data do óbito, caso não } \\
\text { incida outra hipótese de cancelamento } \\
\text { anterior do benefício. }\end{array}$ \\
\hline
\end{tabular}

\section{Auxílio-reclusão}

O auxílio-reclusão foi bastante alterado, como se pode destacar:

(1) Foi criado período de carência, que passou de zero a 24 meses.

(2) O benefício não é devido a todo e qualquer segurado que estiver recolhido à prisão, mas apenas àqueles lá estiverem cumprindo a pena em regime fechado.

(3) O benefício não pode ser pago ao segurado recluso que receber remuneração da empresa ou que estiver em gozo de auxílio-doença, pensão por morte, saláriomaternidade, aposentadoria ou abono de permanência em serviço.

(4) O segurado de baixa renda é aquele que, no mês do recolhimento à prisão, tiver renda de valor igual ou inferior àquela prevista no artigo 13 da EC 20/1998 (R\$ 360), corrigida pelos índices aplicados aos benefícios do RGPS. 
(5) A renda mensal bruta, para fins de enquadramento como segurado de baixa renda, é apurada a partir da média dos 12 últimos salários de contribuição anteriores ao mês do recolhimento à prisão.

As alterações encontram-se a seguir demonstradas:

\begin{tabular}{|c|c|}
\hline Redação anterior à MPv 871 & Redação dada pela MPv 871 \\
\hline $\begin{array}{l}\text { Art. } 80 . \text { O auxílio-reclusão será devido, } \\
\text { nas mesmas condições da pensão por } \\
\text { morte, aos dependentes do segurado } \\
\text { recolhido à prisão, que não receber } \\
\text { remuneração da empresa nem estiver em } \\
\text { gozo de auxílio-doença, de aposentadoria } \\
\text { ou de abono de permanência em serviço. }\end{array}$ & $\begin{array}{l}\text { Art. 80. O auxílio-reclusão será devido nas } \\
\text { condições da pensão por morte, respeitado } \\
\text { o tempo mínimo de carência estabelecido } \\
\text { no inciso IV do caput do art. } 25 \text {, aos } \\
\text { dependentes do segurado de baixa renda } \\
\text { recolhido à prisão em regime fechado, que } \\
\text { não receber remuneração da empresa nem } \\
\text { estiver em gozo de auxílio-doença, pensão } \\
\text { por morte, salário-maternidade, } \\
\text { aposentadoria ou abono de permanência } \\
\text { em serviço. }\end{array}$ \\
\hline $\begin{array}{l}\text { Parágrafo único. O requerimento do } \\
\text { auxílio-reclusão deverá ser instruído com } \\
\text { certidão do efetivo recolhimento à prisão, } \\
\text { sendo obrigatória, para a manutenção do } \\
\text { benefício, a apresentação de declaração de } \\
\text { permanência na condição de presidiário. }\end{array}$ & $\begin{array}{l}\S 1^{\circ} \text { O requerimento do auxílio-reclusão } \\
\text { será instruído com certidão judicial que } \\
\text { ateste o recolhimento efetivo à prisão, } \\
\text { obrigatória, para a manutenção do } \\
\text { benefício, a apresentação de prova de } \\
\text { permanência na condição de presidiário. }\end{array}$ \\
\hline Sem correspondência. & $\begin{array}{l}\S 2^{\circ} \text { O INSS celebrará convênios com os } \\
\text { órgãos públicos responsáveis pelo } \\
\text { cadastro dos presos para obter } \\
\text { informações sobre o recolhimento à } \\
\text { prisão. }\end{array}$ \\
\hline Sem correspondência. & $\begin{array}{l}\S 3^{\circ} \text { Para fins do disposto nesta Lei, } \\
\text { considera-se segurado de baixa renda } \\
\text { aquele que, na competência de } \\
\text { recolhimento à prisão tenha renda, } \\
\text { apurada nos termos do disposto no } \S 4^{\circ} \text {, de } \\
\text { valor igual ou inferior àquela prevista } \\
\text { no art. } 13 \text { da Emenda Constitucional }{ }^{\circ} 20 \text {, } \\
\text { de } 15 \text { de dezembro de } 1998 \text {, corrigido } \\
\text { pelos índices aplicados aos benefícios do } \\
\text { RGPS. }\end{array}$ \\
\hline Sem correspondência. & $\begin{array}{l}\S 4^{\circ} \text { A aferição da renda mensal bruta para } \\
\text { enquadramento do segurado como de } \\
\text { baixa renda ocorrerá pela média dos } \\
\text { salários de contribuição apurados no } \\
\text { período de doze meses anteriores ao mês } \\
\text { do recolhimento à prisão. }\end{array}$ \\
\hline Sem correspondência. & $\begin{array}{l}\S 5^{\circ} \text { A certidão judicial e a prova de } \\
\text { permanência na condição de presidiário } \\
\text { poderão ser substituídas pelo acesso à base }\end{array}$ \\
\hline
\end{tabular}




\begin{tabular}{|l|l|}
\hline & de dados, por meio eletrônico, a ser \\
disponibilizada pelo Conselho Nacional \\
de Justiça, com dados cadastrais que \\
assegurem a identificação plena do \\
segurado e da sua condição de presidiário.
\end{tabular}

\section{Benefício de prestação continuada (LOAS)}

O artigo 26 da MPv modificou, por fim, o artigo 20 da LOAS, para incluir os $\S \S$ 12 e 13. Como já destacado, o § 13 tem vacância de 60 dias, enquanto que o $§ 12$ não está sujeito a vacância. De toda forma, convém observar os novos dispositivos, que firmam requisitos para o requerimento do BPC:

\begin{tabular}{|c|c|}
\hline Redação anterior à MPv 871 & Redação dada pela MPv 871 \\
\hline Sem correspondência. & $\begin{array}{l}\text { Art. 20. (...) } \\
\S 12 \text {. São requisitos para a concessão, a } \\
\text { manutenção e a revisão do benefício as } \\
\text { inscrições no Cadastro de Pessoas Físicas } \\
\text { - CPF e no Cadastro Único para } \\
\text { Programas Sociais do Governo Federal - } \\
\text { Cadastro Único, conforme previsto em } \\
\text { regulamento. }\end{array}$ \\
\hline Sem correspondência. & $\begin{array}{l}\S 13 \text {. O requerimento, a concessão e a } \\
\text { revisão do benefício ficam condicionados } \\
\text { à autorização do requerente para acesso } \\
\text { aos seus dados bancários, nos termos do } \\
\text { disposto no inciso } V \text { do } \S 3^{\circ} \text { do art. } 1^{\circ} \text { da } \\
\text { Lei Complementar } n^{\circ} 105 \text {, de } 10 \text { de } \\
\text { janeiro de } 2001 \text {. }\end{array}$ \\
\hline
\end{tabular}

\section{Resumo das principais alterações e suas consequências}

I - Em razão dos bônus de desempenho, é possível que o INSS passe a nomear, para os processos judiciais, peritos médicos assistentes, para acompanhar ou pelo menos para avaliar as perícias médicas judiciais;

II - Com os programas especial de análise de benefícios e revisional de benefícios por incapacidade, é possível o aumento do número de benefícios suspensos ou cancelados e, consequentemente, dos processos judiciais pelo seu restabelecimento. Cabe recordar que o artigo 69 da LBPS prevê um procedimento administrativo específico;

III - Se houver a perda da qualidade de segurado, não basta mais cumprir metade da carência exigida, é necessário cumprir toda a carência do benefício (auxílio-doença, aposentadoria por invalidez, salário-maternidade e auxílio-reclusão); 
IV - Nos benefícios pagos a dependentes do segurado, que formulem o pedido em razão da existência de união estável com o instituidor, a parte autora deve juntar aos autos início de prova material contemporânea aos fatos, não cabendo prova exclusivamente testemunhal, salvo se comprovar a ocorrência de força maior ou caso fortuito;

V - Em relação ao auxílio-reclusão:

a) O período de carência, antes inexistente, passa a ser de 24 meses, para as prisões ocorridas a partir de 18/01/2019;

b) O benefício só é devido aos segurados presos em regime fechado;

c) O benefício não será pago a segurado que receba remuneração da empresa, auxílio-doença, pensão por morte, salário-maternidade, aposentadoria ou abono por permanência em serviço;

d) A renda mensal bruta que qualifica o segurado como de baixa renda é apurada a partir da média dos 12 últimos salários de contribuição anteriores ao mês do fato gerador (prisão);

VI - Em relação à pensão por morte, seja estatutária, seja previdenciária:

a) Os menores de 16 anos deverão formular o requerimento no prazo de até 180 dias, contados da data do óbito, para que o pagamento seja retroativo ao fato gerador, caso contrário, será devido desde a DER. Esse prazo só se aplica aos fatos geradores (óbitos) ocorridos a partir de 18/01/2019;

b) A concessão não poderá ser postergada em razão da existência de dependente retardatário habilitável;

c) Salvo nos casos de pensão previdenciária, em razão da vacância máxima, a quota devida ao dependente retardatário ficará aprovisionada, sendo paga apenas em caso de sentença procedente transitada em julgado; caso contrário, será dividida entre os já habilitados pensionistas;

d) No caso de alimentos temporários, judicialmente concedidos, decorrentes de casamento ou de união estável, a pensão será devida pelo prazo que faltar na data do óbito, salvo ocorrência de hipótese de cancelamento.

VII - Em relação à aposentadoria por tempo de contribuição:

a) Não cabe, salvo ocorrência de força maior ou caso fortuito, a prova do tempo exclusivamente por testemunha, devendo haver início de prova material contemporânea aos fatos;

b) A prova do tempo de contribuição, mesmo que por justificativa administrativa ou judicial, depende de início de prova material contemporânea aos fatos; 
c) A CTC de ex servidor só pode ser emitida por RPPS;

d) Veda-se a contagem recíproca de tempo entre RGPS e RPPS se a emissão da CTC correspondente;

e) Veda-se a desaverbação do tempo em RPPS quando o tempo averbado tiver gerado a concessão de vantagens remuneratórias ao servidor, quando em atividade;

f) Veda-se a emissão de CTC, com registro do tempo, sem a comprovação de que houve contribuição efetiva, salvo:

1. Nos casos de segurado empregado, empregado doméstico e trabalhador avulso;

2. Se o tempo é anterior à EC 20/1998, quando houver equiparação por lei a tempo de contribuição;

VIII - Em relação à aposentadoria por idade do segurado especial:

a) As informações sobre os segurados especiais passarão a ser registradas no CNIS;

b) A comprovação da condição de segurado especial e do exercício de atividade rural serão feitas:

1. Até 18/03/2019, mediante autodeclaração do segurado;

2. A partir de 19/03/2019 até 31/12/2019, mediante autodeclaração do segurado, ratificada por entidades públicas credenciadas ou outros órgãos públicos;

3. A partir de 01/01/2020, exclusivamente pelas informações constantes do CNIS;

IX - Em relação ao auxílio-doença:

a) O pagamento do benefício será suspenso por 60 dias, para os segurados presos em regime fechado, sendo restabelecido a partir da soltura;

b) O beneficio será cessado se o segurado permanecer preso por mais de 60 dias, em regime fechado;

$\mathrm{X}$ - Apenas os aposentados por invalidez e os pensionistas inválidos com mais de 60 anos de idade são dispensados da perícia revisional;

XI - O salário-maternidade deverá ser requerido dentro do prazo decadencial de 180 dias, contados do parto ou da adoção;

XII - O prazo decadencial decenal passa a valer tanto para os pedidos de revisão de benefícios quanto para os pedidos de concessão. Logo, os requerimentos não podem ter sido indeferidos há mais de 10 anos;

XIII - Em relação aos BPC:

a) As inscrições no CPF e no Cadastro Único passam a ser requisitos para a concessão, a manutenção e a revisão do benefício; 
b) A partir de 19/03/2019, o requerimento, a concessão e a revisão do benefício ficam condicionados à autorização do requerente para acesso a seus dados bancários. 